\title{
Estudo sobre os elementos de uma interpretação invasiva na abordagem psicanalítica winnicottiana
}

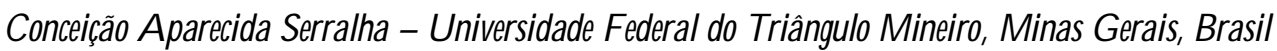

\begin{abstract}
Resumo
Partindo dos textos freudianos, este estudo reapresenta brevemente a técnica da interpretação em psicanálise e, baseandose na obra de Winnicott, discute os elementos de uma interpretação sentida de forma invasiva pelo analisando. São identificados, nomeados e discutidos os elementos apontados por este autor: tempo, modo, graus de confiabilidade, objetividade e conhecimento, sendo ilustrados por alguns fragmentos de sessão de casos de Winnicott e de um caso da autora. $\mathrm{O}$ estudo evidencia a importância da capacidade de 0 analista se identificar com 0 analisando para interpretar, recebendo e entendendo a comunicação deste sobre a adequação de todos esses elementos ao seu caso.
\end{abstract}

Palawasshave Interpretação invasiva; Psicanálise; Winnicott; Relação analista-analisando.

\section{Study on the elements of an invasive interpretation in the Winnicott psychoanalytical approach}

\begin{abstract}
From the Freudian texts, this study reintroduces briefly the technique of interpretation in psychoanalysis and, based on the Winnicott's works, discusses the elements of an interpretation felt invasive by the patient. The elements pointed out by this author and identified, named and discussed include: time, manner, degrees of trustworthiness, objectiveness and knowledge. They are illustrated with fragments of session of Winnicott's cases and one case of the author. The study highlights the importance of the analyst's capacity of identifying him/ herself with the patient to interpret, receiving and understanding his/ her communication on the adequacy of all these elements in his/ her case.

Kegrads Invasive interpretation; Psychoanalysis; Winnicott; Analyst-patient relationship.

Estudio sobre los elementos de una interpretación invasiva en el abordaje psicoanalítico winnicottiano

Resumen

Partiendo de los textos freudianos, este estudio reapresenta brevemente la técnica de la interpretación en psicoanálisis y, basándose en la obra de Winnicott, discute los elementos de una interpretación sentida de forma invasiva por el analizando. Son identificados, nombrados y discutidos los elementos apuntados por este autor: tiempo, modo, grados de confiabilidad, objetividad y conocimiento, siendo ilustrados por algunos fragmentos de sesión de casos de Winnicott y de un caso de lo autor. El estudio evidencia la importancia de la capacidad de el analista identificarse con el analizando para interpretar, recibiendo y entendiendo la comunicación de este sobre la adecuación de todos esos elementos a su caso.

Palabrasdave Interpretación invasiva; Psicoanálisis; Winnicott; Relación analista-analizando.
\end{abstract}

A interpretação, na psicanálise, é a tarefa prática do analista, a técnica utilizada, em especial, para "transformar o sonho manifesto em sonho latente" para, na sequência, realizar sua tarefa teórica, ou seja, explicar como este sonho se tornou manifesto na mente do sonhador - processo de elaboração onírica (Freud, 1972c, p. 20). Segundo Freud, a interpretação é necessária para "transpor o hiato" (p. 24) entre os pensamentos oníricos, em razão de os sonhos não fornecerem fielmente um conhecimento sobre esses pensamentos. Em suas palavras, há "uma comunicação feita por meios inadequados [...]. Na verdade nem nós compreendemos o que o sonhador tenta dizer-nos, e ele próprio igualmente ignora" (p. 19). Essa ignorância do sonhador se deve a um processo de censura onírica, uma resistência à passagem dos conteúdos reprimidos no inconsciente para a consciência, exercida pelas mesmas forças que os reprimiram (Freud, 1972f).

A interpretação também é aplicada à elucidação de outras produções do inconsciente, como os sintomas, os atos falhos, os lapsos etc. (Laplanche \& Pontalis, 1992), e essas produções, da mesma forma que 0 sonho manifesto, resultam do êxito obtido pelo paciente na repressão de certas ideias e lembranças fortemente catexizadas com afeto, assim como dos desejos que delas se originam [...], permanecendo assim desconhecidos para ele. É desse material psíquico reprimido (desses 'complexos') que derivam os sintomas somáticos e psíquicos que atormentam 0 paciente [...] (Freud, 1972d, p. 110).

Dessa maneira, para Freud (1972b; 1972e), o objetivo principal da interpretação é evidenciar 0 desejo inconsciente do sujeito (analisando), como também a fantasia originada desse desejo, ampliando 0 seu autoconhecimento e fortalecendo o seu ego. Para 0 trabalho puramente intelectual da interpretação, 0 analista vai se valer de algum desses elementos isolados do material oferecido pelo analisando, como uma associação, uma parapraxia, ou um sonho, preenchendo provisoriamente "as lacunas" no "patrimônio mental" deste (1972e, p. 209). Contudo, para Freud, o trabalho do analista não se resume em interpretar, mas consiste também em construir "aquilo que foi esquecido a partir dos traços que deixou atrás de si" (p. 293), em colocar "perante o sujeito da análise 
um tragmento de sua historia primitiva, que ele esqueceu" (p. 295).

Sobre o uso da interpretação, Freud (1972e) alertou para a importância de uma "distinção rigorosa" entre 0 conhecimento do analista e o conhecimento do analisando; 0 analista evitando dizer a este a "totalidade" do que descobriu. Esse procedimento, segundo Freud, permite que 0 analista adie ao máximo comunicar a sua construção até que 0 analisando "tenha chegado tão perto dela que só reste um único passo a ser dado", momento em que o conhecimento do analista se torna também o conhecimento do analisando (p. 205). Além disso,

a ocasião e o modo como transmite suas construções à pessoa que está sendo analisada, bem como as explicações com que as faz acompanhar, constituem o vínculo entre as duas partes do trabalho de análise, entre seu próprio papel e o do paciente" (Freud, 1972e, p. 293).

Caso não haja esse cuidado, a informação do analista "ou não produziria efeito algum ou, então, provocaria uma violenta irrupção da 'resistência"' (Freud, 1972e, p. 205), dificultando o trabalho ou interrompendo-o completamente.

Winnicott (1994a), por sua vez, descreveu o termo interpreação como o uso feito pelo analista de palavras para tentar levar 0 analisando a compreender 0 material trazido para a sessão. Seria ainda a maneira - por meio da linguagem - de demonstrar ao analisando a compreensão do analista sobre as ideias e os sentimentos dele (analisando), necessária ao estabelecimento da confiança do analisando no analista (Winnicott, 1990c). D estacou, como já era reconhecido entre os psicanalistas da época, que 0 analisando podia trazer esse material de várias maneiras e, quando o fazia de forma verbal, essa fala envolvia "muito mais que 0 significado das palavras utilizadas". Ao observar que "uma grande parte da comunicação que se dá do paciente para o analista não é verbalizada", chamou a atenção para 0 fato de que, muitas vezes, movimentos, comportamentos e silêncios do analisando são também interpretados (Winnicott, 1994a, p. 163).

Winnicott (1999) salientou que, no material trazido pelo analisando por meio dessas diversas formas, "há uma tendência que pede uma verbalização" e 0 analista sente isso ( $p$. 85). Assim, ele também atenta para a participação mútua do analista e do analisando na ocorrência da interpretação. Freud descreveu esse sentimento do analista como uma capacidade de "apreender o curso do inconsciente do paciente com 0 seu próprio inconsciente" (Freud, 1972g, p. 291).

Winnicott, assim como Freud, ressaltou a importância do ato de interpretar adequadamente para o bom desenvolvimento da análise. Para ele, os efeitos da interpretaçao e 0 desenrolar da análise dependem "da maneira como o analista usa as palavras", o que traduz "a atitude que se oculta por trás da interpretação" (Winnicott, 1999, p. 85). Além desse elemento - modo (maneira) - , outros elementos foram apontados por Winnicott, e alguns já o haviam sido por Freud, como interferentes na forma como a interpretação é recebida e sentida pelo analisando.

Proponho que um dos sentimentos vividos pelo analisando, ao ser interpretado, possa ser comparado ao que ele sente quando de uma invasão ou intrusão (impingment), que, segundo Winnicott, constitui-se na interrupção da continuidade do ser do indivíduo por fatores ambientais em razão de falhas do ambiente facilitador (Winnicott, 1994b). Assim, este estudo pretende discutir os elementos contextuais de uma interpretação psicanalítica - tempo, modo, graus de confiabilidade, objetividade e conhecimento -, principalmente quando esses elementos interferem de modo a possibilitar, no analisando, o sentimento de ter sido invadido, ao que denominei intepretação invasiva Para alcançar esse objetivo, foi realizada uma leitura de textos psicanalíticos sobre o tema, em especial da obra winnicottiana, analisando-os e utilizando alguns fragmentos de sessão de casos atendidos por Winnicott e de um caso meu, para fins de ilustração.

\section{A intepretacãoinvasiva}

Interpretações, principalmente do nãoverbalizado, podem ser sentidas pelo paciente de forma invasiva, como apontou um analisando de Winnicott ao lhe fazer entender que "a menos que ele [0 analisando] houvesse verbalizado sua comunicação, não cabia a mim [Winnicott] fazer comentários" (Winnicott, 1994a, p. 163). Esse sentimento surge no analisando, porque 0 analista se torna perigoso ao se aproximar em demasia da "comunicação com o núcleo central quieto e silencioso da organização do ego do paciente" (Winnicott, 1990a, p. 172), que não está acessivel a este e que, na verdade estará "permanentemente desconhecido, na realidade, nunca encontrado" (p. 170). Com isso, 0 analisando perde a espontaneidade, precisa se vigiar e se defender, conforme constatado no caso acima descrito, no momento em que Winnicott interpretou o movimento dos dedos da mão do analisando sobre o próprio peito e este disse: "Se você começar a interpretar esse tipo de coisas, vou ter de transferir esse tipo de atividade para outra que não apareça" (Winnicott, 1994a, p. 163).

A interpretação invasiva acontece quando há um descompasso do analista com o analisando e não é uma característica exclusiva de psicanálise setvagm embora a invasão seja a tônica desta. Em 1910, Freud empregou pela primeira vez esse termo ao descrever o erro de um 
analista novato e inexperiente de interpretar, no primeiro contato, o material reprimido de sua paciente. Segundo Freud, "a intervenção psicanalítica [...] requer de maneira absoluta um período bastante longo de contato com o paciente" (Freud, 1972a, p. 211). A interpretação invasiva, por sua vez, pode estar presente em toda e qualquer análise, e em qualquer fase desta, mesmo no trabalho de analistas experientes, em razão da falibilidade própria à natureza humana.

No trabalho de um analista suficientemente bom, o que é observável é a capacidade deste de evitar que 0 grau de invasão da interpretação seja alto demais, ou, pelo menos, se isso se tornar impossível, de reparar os danos que tal invasão possa provocar. Além disso, para Winnicott, em determinados casos, não interpretar pode trazer mais prejuízos ao analisando do que interpretar, já que deixar de interpretar pode levá-lo a crer que "ninguém vai entender" (Winnicott, 1994c, p. 248).

\section{O demento confiabilidadedoanalista}

De acordo com Winnicott (1975a), o principal elemento propiciador de uma boa análise é o gau de confiança na fidedignidade do terapeuta. Nota-se que, se for um analista fidedigno, o que vier deste será sentido/ entendido como interesse de compreender e ajudar, e não de se apossar, submeter ou aniquilar. A partir desse sentimento/ entendimento, a confiança pode se desenvolver naturalmente. Em certa ocasião, ele descreveu assim o trabalho de interpretação de um analista, que não teve oportunidade de prosseguir 0 tratamento:

Ele fez a interpretação, portanto, correndo por isso o risco de estragar o trabalho que já havia sido feito, mas também abrindo a possibilidade de que a paciente pudesse ir mais além imediatamente. Esta é uma questão de julgamento e 0 analista sentiu aqui que o grau de confiança era tal que ele podia prosseguir e até mesmo cometer um erro (Winnicott, 1994a, p. 166).

Esse julgamento tem por base um processo de identificação. Winnicott (1975a) evidenciava no stting da análise, ou seja, no ambiente que se constitui na relação do psicanalista com 0 seu analisando, características presentes na relação satisfatória do indivíduo com o seu ambiente inicial, formado por aqueles que exercem os papéis parentais. D entre essas características destacam-se, principalmente, a sustentação (hdding, em que 0 ambiente, ao exercer 0 papel materno, se identifica com o seu bebê, conhece-0 e 0 atende em suas necessidades, e também 0 manejo (management), em que situações da realidade externa são administradas para permitir a continuidade de ser do bebê, que, com o passar do tempo, vai de uma condição de dependência à autonomia. 0 ambiente confiável é, portanto, "facilitador, materno e terapêutico" (Dias, 1999, p. 283). Segue-se uma das passagens em que essa analogia mãe-analista é feita por Winnicott:

na experiência que 0 bebê tem da vida, na realidade em relação à mãe ou figura materna, se desenvolve geralmente certo grau de confiança na fidedignidade da mãe, ou (em outra linguagem, própria da psicoterapia), o paciente começa a sentir que 0 interesse do terapeuta não se origina da necessidade de um dependente, mas de uma capacidade, nesse terapeuta, de se identificar com o paciente, a partir de um sentimento do tipo 'se eu estivesse em seu lugar' (Winnicott, 1975a, p. 150).

$\mathrm{Na}$ falta dessa capacidade, instala-se a nãoconfiabilidade do analista, fator que pode fazer com que uma interpretação seja sentida de forma invasiva pelo analisando, uma vez que soará estranha pela falta de identificação. Contudo, outros elementos também colaboram para esse sentimento e, na verdade, esses elementos encontram-se sempre inter-relacionados, podendo ser identificados, mas não pressupostos como tendo uma influência absoluta ou isolada.

\section{Os dementos tempo, modbegraus dedjieividadeeconheimento}

Além da fidedignidade ou confiabilidade do analista, pode ser apontado um segundo elemento, 0 tempo relacionado ao momento em que uma interpretação é feita. Esse momento da realização de uma interpretação é influente não só quando se refere ao quantum de amadurecimento que 0 analisando alcançou no tempo e que vai lhe permitir aceitar ou recusar a interpretação como uma projeção sua, como também quando se refere ao intervalo que ocorre entre a produção do material pelo analisando e a interpretação deste material pelo analista.

Sobre o primeiro aspecto, Winnicott (1994d) adverte que o tempo adequado da interpretação requer que 0 paciente tenha conquistado, inicialmente, em razão dos cuidados suficientemente bons do analista, a capacidade de fazer projeções para este. Em discussão sobre esse assunto, Winnicott disse que, a menos que 0 paciente seja capaz de projetar para o analista seus fatores internos satisfatórios, "a análise boa (seio bom) constitui essencialmente um objeto persecutório para 0 paciente (bebê)" (p. 347).

Sendo assim, com um paciente ainda incapaz de fazer esse tipo de projeções ao analista, o trabalho psicoterapêutico prescinde da interpretação. Diferentemente de Klein, que teorizava uma capacidade do bebê de projetar e introjetar desde 0 início de sua vida, Winnicott acreditava que essa 
capacidade do bebê requeria amadurecimento; para tanto o bebê já deveria ter uma noção de EU e Não EU (Dias, 2007). Assim, ao aproximar a relação analista-analisando da relação mãe-bebê e entender a possibilidade de uma regressão à dependência, ou de uma vivência da dependência pela primeira vez no contexto analítico, algumas interpretações, mesmo que corretas, se tomariam ameaças. Isso aconteceria exatamente pelo fato de a interpretação levar 0 analisando ao conhecimento de algo que ele ainda não teria condições de abarcar por não ter atingido um estágio de desenvolvimento emocional - ou por este ter sido abalado ou interrompido - "como personalidade total", que lhe permitiria isso. A interpretação, nesse caso, poderia conduzir 0 analisando para "além do que a confiança transferencial permite” (Winnicott, 1994a, p. 166). Um exemplo pode ser encontrado na análise da pequena Gabrielle (Pigge), feita por Winnicott. Em determinada sessão, ele antecipou o momento em que ela poderia lidar com 0 que ele evidenciou, ao interpretar: "Você estava com medo de achar que você queria fazer bebês comendo os navios". Gabrielle então respondeu: "Posso dizer 'Alô' para o papai?". Ela foi até o pai, que tentou convencêla a voltar. Após o fracasso dessas tentativas, ela voltou e disse: "Não vou voltar mais" (Winnicott, 1987, p. 70); e, de fato, Gabrielle não quis mais voltar para a sessão.

Ao entender as ansiedades de Gabrielle associadas ao "fazer bebês comendo" (p. 71), Winnicott interpretou, mas ela não conseguiu prosseguir. Nesse momento, e em outros semelhantes a esse, Winnicott compreendia o quanto era importante para Gabrielle buscar a proteção do pai. Ela, provavelmente, poderia ter se utilizado de defesas mais primitivas para se proteger do aumento da ansiedade, gerado no contato com algo que seu grau de maturidade não poderia abarcar, caso não pudesse contar com o clo do pai (Serralha, 2009).

O outro aspecto relacionado ao tempo da interpretação diz respeito ao fato de que, mesmo que a interpretação seja feita a uma pessoa que já atingiu um bom desenvolvimento como personalidade total, 0 material que ela produz para ser interpretado origina-se de apenas uma parte de sua pessoa total em um dado momento da análise, e somente nesse momento a interpretação pode ser útil. Para Winnicott, "como pessoa total, 0 paciente não teria sido capaz de ter fornecido o material para a interpretação" (1994a, p. 164). Ao comentar um momento como esse, ele disse: as interpretações fazem parte de uma construção de insight. Detalhe importante é que a interpretação foi dada dentro de um certo número de minutos ou mesmo segundos do material muito rico em insight que foi apresentado. Ela certamente é dada na mesma sessão analítica. A interpretação correta, dada no dia seguinte, após uma supervisão, não tem utilidade, por causa desta operação muito poderosa de um fator temporal. (1994a, p. 165).

Ao ser extemporânea, essa informação pode ser não apenas inútil, mas também invasiva. Em uma situação como essa, 0 analisando pode se defender recusando a interpretação, duvidar da capacidade do analista de entendê-lo, sentir-se confundido com outro pelo analista, ficar assustado - como ficou Gabrielle ou, ainda, enraivecido com a invasão.

Esse ponto abre caminho para o exame do terceiro elemento que pode fazer com que uma interpretação seja sentida como invasiva, que é o mob como é feita a interpretação. Na análise, a fala do analista pode acontecer de duas formas. Na primeira, considerada por Winnicott como a mais simples, "0 analista devolve ao paciente o que este comunicou" (1994a, p. 165). Nota-se que essa forma tem o efeito de propiciar ao analisando o sentimento de que ele foi ouvido e compreendido, e a fala do analista o endvesem sentimentalismo - dando-lhe sustentação e transmitindo confiança. A segunda forma, uma interpretação propriamente dita, pendra 0 mundo do analisando, o que não é necessariamente invasivo, uma vez que pode vir a iluminar o que já estava ali para ser visto.

Para que se possa entender o que Winnicott discute sobre esse terceiro elemento, é importante recordar duas colocações feitas por ele: a primeira, de que "a lentidão do processo analítico é manifestação de uma defesa que 0 analista tem de respeitar, tal como respeitamos todas as defesas" (Winnicott, 1994e, p. 134); e a segunda, de que "a verbalização no momento exato mobiliza forças intelectuais" e que "só é ruim mobilizar os processos intelectuais quando estes se tornaram seriamente dissociados do ser psicossomático [...]" (Winnicott, 1994f, p. 153). Assim, mesmo que a interpretação seja feita no momento certo, o modo, ou a lingragem com a qual a interpretação é feita é o elemento com 0 qual 0 analista pode respeitar as defesas do analisando de uma forma que este não se dissocie seriamente. Embora Winnicott (1984) reconhecesse a influência da resistência quando da negação de uma interpretação correta, 0 mais importante era perceber que essa negação constatava um erro de sua parte em relação ao momento ou à maneira com a qual verbalizava 0 material, principalmente em razão da diferença que existe no trabalho realizado conforme a pessoa seja mais ou menos amadurecida. 
Segundo Winnicott (1990c), quando se analisa uma pessoa que ainda é muito imatura, o essencial ao analista é que ele seja capaz de "suportar a regressão real à dependência” (p. 80). Mas, quando se analisa uma pessoa que já percorreu uma boa distância em sua linha do amadurecimento e que pode ser considerada psiconeurótica, o que será essencial ao analista é que ele seja capaz de tolerar ideias, sentimentos e a ambivalência destes. Além disso, ele deverá ser capaz de compreender os processos inerentes aos conflitos e

demonstrar essa compreensão pela expressão adequada através da linguagem (a interpretação daquilo que 0 paciente está justamente em condições de admitir conscientemente). [...] A compreensão penetra mais fundo, e através da compreensão demonstrada pelo uso [adequado] da linguagem, 0 analista embala 0 paciente fisicamente no passado, ou seja, na época em que havia necessidade de estar no colo, quando 0 amor significava adaptação e cuidados físicos (Winnicott, 1990c, p. 80).

Já a linguagem inadequada é invasiva e, se for fácil demais, pode seduzir o analisando. Nesse caso, 0 material produzido pelo analisando fica comprometido, pois pode ser fruto da linguagem sedutora do analista (Winnicott, 1990c).

Sobre o quarto elemento, o gau de djeividade do objeto (analista) que 0 analisando pode alcançar, um dos momentos em que Winnicott (1994c) discute sobre isso é quando ele mostra a característica do material fornecido na primeira entrevista - relativamente não"defendido". Para ele, essa característica ocorre em razão de, nessa entrevista, o analista ser um "objeto subjetivo" para 0 analisando. 0 analista ainda não é percebido como um indivíduo (objeto) separado, capaz de se apropriar de um conhecimento sobre 0 analisando que este próprio não tem e que tornaria 0 primeiro perigoso e ameaçador (1994c, p. 244-5).

$\mathrm{Na}$ análise, o analista é concebido subjetivamente pelo analisando na transferência - "ao assumir o papel de uma ou outra figura confiável da infância do paciente" (Winnicott, 2000, p. 280), ou "ser a primeira pessoa a fornecer certos elementos essenciais do ambiente" (p. 282) - e a percepção objetiva dele por parte do analisando vai ocorrendo à medida que 0 analista vai se tornando externo e real para ele, de uma forma compartilhada com outras pessoas. Essa percepção sem necessidade de defesa por parte do analisando decorre do desenvolvimento do seu intelecto e de um ambiente confiável. Esse ambiente respeita o grau de externalidade possível em cada momento da análise, ou seja, está de acordo com a capacidade amadurecida do analisando de lidar com essa realidade externa de forma objetiva. Todo 0 trabalho de interpretação a ser realizado terá de acompanhar a capacidade do analisando de "situar 0 analista fora da área dos fenômenos subjetivos" (Winnicott, 1994g, p. 172).

Quando Winnicott (1990b) entende sua posição no trabalho de análise como "um fenômeno de transição", que, ao mesmo tempo em que representa 0 princípio de realidade, é também objeto subjetivo para 0 paciente (p. 152-3), ele mostra como o termo objetividade é relativo (Winnicott, 1975b, p. 96). Segundo Winnicott (1975b), existe uma variação do grau de objetividade no que se refere à realidade externa para um determinado indivíduo, em determinado momento. Esse grau se relaciona com sua condição emocional e/ ou intelectual, bem como com a regressão à dependência; quanto mais regredido a esta, menor 0 grau de objetividade e, "na medida, que 0 objeto é subjetivo, é desnecessário que a comunicação com ele seja explícita” (Winnicott, 1990a, p. 166). Ser e se manter como objeto subjetivo para 0 analisando, não fazendo ou não dizendo algo que seja "estranho ao material do paciente disponível para projeção", é importante para que a qualidade externa do analista, que se origina desse fazer ou dizer, não o torne um perseguidor, caso haja impossibilidade real do analisando de uma percepção mais objetiva (Winnicott, 1990b, p. 153). Winnicott contou que, no caso de seu paciente (Bob) de seis anos de idade, somente um ano após as consultas realizadas, 0 garoto pareceu conseguir objetivá-lo. Segundo ele, "acho que se pode dizer que ele estava em processo de me objetivar e que eu estava emergindo (para ele) da categoria de objeto subjetivo, ou que o sonho se tornava realidade" (Winnicott, 1984, p. 99).

Com analisados menos imaturos, Winnicott sentia a necessidade, vez ou outra durante a análise, de arriscar fazer ou dizer alguma coisa sem muita exatidão, para que 0 analisando não ficasse com a impressão de que ele - Winnicott - compreendia tudo (1994d). Um de seus princípios era 0 de que "é 0 paciente, e somente ele quem tem as respostas" (Winnicott, 1994g, p. 171-172).

Encontra-se aqui, então, um quinto elemento desse conjunto, o grau de conheimento que se refere a duas coisas: quanto conhecimento para além do saber atual do analisando a interpretação pode introduzir sem invadir, como também quais são os limites da compreensão do analista. Em uma nota, durante a análise de Gabrielle sobre o desenrolar da sessão, Winnicott escreveu: "Importância da minha incompreensão do que ela ainda não tinha sido capaz de dar-me indícios. Somente ela sabia as respostas e, quando conseguiu apreender o significado de seus medos, tomou possível que eu os compreendesse 
também" (1987, p. 54). Nesse ponto, Winnicott destaca 0 quanto foi importante para Gabrielle e para 0 desenvolvimento do trabalho em sessão o fato de ele não se adiantar com uma interpretação que pudesse ser construída a partir de sua experiência analítica e de sua teoria adquirida nesta sobre crianças. Acompanhandoa, aguardando que ela pudesse lhe indicar um sentido, 0 que ele pôde compreender e dizer não foi invasivo, uma vez que ela própria já havia alcançado uma compreensão que a conduziu a uma resolução, mesmo que parcial, de seus medos, esquecendo-os. Ao final do relato dessa sessão, Winnicott disse: "Continuei sentado no chão enquanto ela saía muito feliz pela porta da frente, em companhia do pai" (p. 53). Podese, assim, perceber, em Winnicott, um entendimento do processo que vai em direção oposta à de Freud (1972e): o de que o conhecimento do analisando se torna o conhecimento do analista.

Para ilustrar e, consequentemente, explicar esse elemento, um fragmento de uma sessão da análise de um garoto de 9 anos, atendido por mim, no segundo ano dessa análise, é apresentado a seguir.

\section{A invasãodeumflagrante}

Nesse dia, em razão do trânsito entre a minha residência e meu consultório, houve um atraso de cinco minutos para a sessão. Por não ter secretária, 0 consultório, situado em uma sala de um edifício, ficava fechado e só era aberto por mim. Como se tornou costume após um tempo, a pedido do garoto, a mãe 0 deixou subir sozinho após pedir ao porteiro que 0 observasse por meio das câmeras do circuito interno de segurança. Ao encontrar o consultório fechado, ele ficou aguardando no hall do elevador. Quando eu saí do elevador, o garoto estava encostado à parede, olhando para a porta deste. Seu olhar era o de uma criança que se sentia perdida, e isso fez com que eu me lembrasse de algumas situações vividas por ele em seu primeiro ano de vida, relatadas pela mãe. Dirigi-me a ele e lhe pedi desculpas pelo atraso. Perguntei-lhe: "Você achou que eu o tinha esquecido?" Ele confirmou, mas, imediatamente, disfarçando seus sentimentos, disse: "D esta vez ganhei de você... cheguei primeiro!" Concordei e caminhamos juntos até 0 consultório.

D urante a sessão, começou a contar histórias com a minha participação, cujas personagens estavam muito agressivas. Em um dado momento, quando o meu braço, em um movimento da personagem, aproximouse dele, ele tentou me morder, chegando a raspar-me os seus dentes. Eu o olhei e perguntei-lhe o que estava acontecendo. Ele desconversou. Disse-lhe: "Acho que você está com muita raiva de mim por eu ter me atrasado e por você ter levado muito susto com isso, não é mesmo?" Nervoso, ele negou. Continuei: "Você ficou muito assustado!!... Achou que eu o tinha esquecido!!..." Mais nervoso ainda, ele gritou: "Eu não me assustei... eu não me assustei..." e, levantando-se do banquinho à volta da mesa onde estávamos sentados, dirigiu-se à janela e tentou atirar para fora, através da rede de proteção, o bicho de brinquedo que carregava. Vi surgir, no garoto, o pavor de ser flagrado em sua fragilidade e necessidade de manter tudo sob controle e, sentindo-se humilhado e desconsiderado em sua necessidade, defendeu-se agressivamente.

Nessa sessão, eu pude me aproximar da dimensão da sua agonia diante da possibilidade de reviver a quebra de uma confiança, de se desiludir precocemente ao ser confrontado, de forma imprevista, com um conhecimento de si para o qual não estava preparado. Ficar com raiva de mim foi muito importante; isso sinalizava que ele sabia que fui eu quem falhou com ele, mostrando ter condições de se perceber separado do Não-Eu, embora, conforme todo o processo de análise até então demonstrou, não tivesse um si-mesmo suficientemente integrado. A minha falha me colocou como um objeto externo ao mundo subjetivo dele, mas 0 atordoamento provocado pelo imprevisto dificultoulhe perceber-me mais objetivamente. Para Winnicott, “a mudança do objeto de 'subjetivo' para 'percebido objetivamente' é realizada menos efetivamente por satisfações do que por frustrações" (1990a, p. 165). Contudo, se for um acontecimento extemporâneo à condição maturativa emocional do indivíduo, a objetividade fica dificultada e a agonia toma lugar.

$\mathrm{Eu}$ pude perceber, principalmente, que os sentimentos do garoto não foram apenas por eu ter falhado com o meu atraso para a sessão, fazendo-o reviver antigas sensações nesse sentido, uma vez que isso estava lá, tornado-se consciente para ele. $\mathrm{Na}$ verdade, a maior parte de sua raiva foi por eu ter flagadbe denunciado o seu "assustamento" - momento repleto de fantasias e sentimentos, arrastado no tempo, que a palavra "susto" não consegue dar a entender que ele não podia se dar conta e, sendo assim, era um conhecimento extremamente invasivo e humilhante para ele. Era o reconhecimento de sua vulnerabilidade e impotência ante algumas situações. A impossibilidade de prever e controlar tudo, era algo de que ele ainda não era capaz de tomar consciência, ultrapassava todas as suas defesas, jogava por terra a imagem idealizada de si. Ante a minha interpretação, ele negou e eu insisti. Eu não reconheci o limite da criança e o meu próprio limite naquele momento. Essa compreensão só me foi possível, posteriormente, ao analisar sua reação, quando esta me trouxe o conhecimento que eu não havia tido até então. 
Ao discutir sobre 0 propósito da interpretação, Winnicott disse: "Tenho sempre sentido que uma função importante da interpretação é 0 estabelecimento dos limites da compreensão do analista" (1990a, p. 172). Para tanto, todos os elementos aqui discutidos precisam ser observados. Os sinais, que 0 analisando emite, são diversificados, e 0 analista precisa estar atento para recebê-los e entendêlos; reações de raiva e agressivas não são as únicas evidências de limite transposto. $\mathrm{Na}$ análise do caso B, atendido por Winnicott (1991), por exemplo, este comentou que, "apesar de [0 paciente] ter dito 'sim' todas as vezes que adormecera, era como se o paciente não houvesse realmente escutado a minha interpretação" (p. 117). Segue-se um pequeno fragmento de uma sessão de B em que isso aconteceu:

Padente "Parece que hoje eu caí no sono várias vezes. Isso deve ser importante."

Analista: "Acho que você não ouviu o que eu disse. Eu falei que, como o seu pai estava doente, você tinha de protegê-lo" (Eu repeti a interpretação).

Paciente "Essa observação talvez seja não tanto abstrata mas despropositada: a dificuldade aqui é que não pode haver um simples retraimento, como, por exemplo, num encontro social onde eu não preciso conversar se eu não quiser fazê-lo. Aqui, eu tenho que ir mais adiante para escapar da situação." (p. 157).

Ao transpormos os limites do analisando e 0 nosso como analistas, "obrigamos" o analisando a usar todos os seus recursos conscientes e inconscientes para escapar de uma invasão.

No fragmento de sessão do caso por mim atendido, pode ser notada a influência dos outros elementos para o caráter invasivo da interpretação realizada, além da introdução de um conhecimento que a criança ainda não podia abarcar. Nota-se que a minha colocação como um objeto externo, extemporaneamente, dificultou-lhe ver-me de forma objetiva e eu me tornei, por um momento, ameaçadora. Além disso, o modo como repeti a interpretação categoricamente afirmativa, ignorando sua negação anterior, não lhe permitiu outra reação ante a invasão que sentiu. Entretanto, as falhas do analista não destroem tudo. De acordo com Dias (1999), "quando as falhas são ocasionais e não chegam a constituir um padrão e 0 ambiente é genuinamente preocupado com o indivíduo, elas são corrigidas e, nesse caso, a par do trauma relativo, algo de muito importante acontece" (p. 318). A minha falha no caso aqui apresentado não destruiu tudo, pois eu havia conseguido, durante 0 tempo de análise até então, tornar-me confiável ao pequeno analisando; havia uma história de nossa relação. Embora, momentaneamente, essa confiabilidade tenha sido abalada, passado o terror inicial de ter sido flagrado e invadido, ele pôde rever e acreditar no interesse que eu tinha de ajudá-lo; como ele mesmo disse ainda nesta sessão, ele já me conhecia "há dois mil anos..."

\section{Considerações finais}

Ao final desta exposição, fica claro que a influência de cada elemento não ocorre isoladamente. A interpretação também não traz resultados independentes de outros componentes da análise, como a pessoa do analista, a pessoa do analisando e, em especial, a relação analista-analisando. 0 que aflora o caráter invasivo de uma interpretação, a ponto de esta ser assim sentida pelo analisando, portanto, são as características com as quais todos os componentes se apresentam e se relacionam no sttinganalítico.

Como se evidencia na obra de Winnicott, a especificidade de uma análise suficientemente boa não se encontra no saber antecipado do analista sobre 0 tempo certo, o modo adequado e os graus suficientes de confiabilidade, objetividade e conhecimento para a realização de uma interpretação, mas na capacidade de se manter identificado com o analisando e com isso receber e entender, à medida que interpreta, a comunicação deste sobre a adequação de todos os elementos ao seu caso particular. Se existe essa identificação, o analista torna-se cuidadoso; pode ir se adequando e reparando falhas. Com isso - e não com uma atuação sem falhas - ele é sentido e percebido, pelo analisando, confiavelmente, 0 que lhe possibilita conduzir a análise de forma satisfatória.

Em situações de análise bastante específicas, 0 analista não tem como saber de antemão, por exemplo, o quanto ou como a sua fala provocará mudanças na maneira como 0 analisando está se relacionando com ele, o quanto de subjetividade ou objetividade está permeando a relação naquele momento. Há uma sutileza nisso e 0 analista terá de esperar uma comunicação do analisando - de qualquer tipo, verbal ou não-verbal - para se dar conta da consequência de sua interpretação. 0 mesmo ocorre em relação aos outros elementos. 0 essencial é que 0 analista não fique preocupado com essa questão, pois a capacidade de se identificar com 0 analisando exige-lhe que se mantenha minimamente espontâneo.

Essa espontaneidade, por outro lado, cria a possibilidade concreta de falha, e consequentemente de invasão, e essa possibilidade precisa ser integrada pelo analista que quer entender e ajudar. Caso 0 analista não assuma esse risco, ele terá apenas duas alternativas: calar-se, para evitar a falha e levar 0 analisando a ter a 
ilusão de sua onisciência, ou interpretar oniscientemente, negando a própria falibilidade, ignorando a comunicação e/ ou reações do analisando e impedindo a real compreensão do sofrimento deste.

\section{Referências}

Dias, E. O. (1999). Sobre a confiabilidade: decorrências sobre a prática clínica. Naturधza Humana, 1(2), 283-322.

Dias, E. O. (2007). Incorporação e introjeção em Winnicott. Winnicatt ePrints Série 2, vol. 2, n. 2, pp. 1-30. Disponível: em http:/ / www.centrowinnicott.com.br/ winnicott_e print

Freud, S. (1972a). Psicanálise 'Silvestre'. Em Edição Standard Brasilera das Obras Completas de Sigmund Frend (pp. 205-213, J. Salomão \& cols., trad., vol. $\mathrm{XI}$ ). Rio de Janeiro: Imago. (O riginal publicado em 1910).

Freud, S. (1972b). O manejo da interpretação de sonhos na psicanálise. Em Edição Standard Brasileira das Obras Completas deSigmund Fread (pp. 119-127, J. Salomão \& cols., trad., vol. X I). Rio de Janeiro: Imago. (O riginal publicado em 1911).

Freud, S. (1972c). Novas conferências introdutórias sobre psicanálise. Em Edição Standard Brasilera das Obras Compleas de Sigmund Freud (pp. 13-177, J. Salomão \& cols., trad., vol. XXII). Rio de Janeiro: Imago. (O riginal publicado em 1933 [1932]).

Freud, S. (1972d). A psicanálise e a determinação dos fatos nos processos juńdicos. Em Edição Standard Brasilera das Obras Compleas deSigmund Frend (pp. 101-115, J. Salomão \& cols., trad., vol. IX). Rio de Janeiro: Imago. (O riginal publicado em 1906).

Freud, S. (1972e). Esboço de psicanálise. Em Edição Standard Brasilera das Obras Completas de Sigmund Frend (pp. 165-329, J. Salomão \& cols., trad., vol. XX III). Rio de Janeiro: Imago. (O riginal publicado em 1940 [1938]).

Freud, S. (1972f). Cinco lições de psicanálise. Em Edicão Standard Brasileira das Obras Completas de Sigmmd Frend (pp. 13-51, J. Salomão \& cols., trad., vol. XI). Rio de Janeiro: Imago. (O riginal publicado em 1910 [1909]).

Freud, S. (1972g). D ois verbetes de enciclopédia. (A) Psicanálise. Em Edição Standard Brasilèra das Obras Completas de Sigmmd Freud (pp. 287-307, J. Salomão e cols., trad., vol. XVIII). Rio de Janeiro: Imago. (O riginal publicado em 1923[1922]).

Laplanche, J., \& Pontalis, J. B. (1992). Vocabulánio da psicanálise (P. Tamen, trad.). São Paulo: Martins Fontes.
Serralha, C. A. (2009). Winnicott com Gabrielle e seus pais. Natureza Humama, 11(1), 155-170.

Winnicott, D. W. (1975a). O lugar em que vivemos. Em D. W. Winnicott (Ed.), O brincar ea realidade (pp. 145-152, J. O. A. Abreu \& V. Nobre, trad.). Rio de Janeiro: Imago. (Original publicado em 1971).

Winnicott, D. W. (1975b). A criatividade e suas origens. Em D. W. Winnicott (Ed.), O brincar ea realidade(pp. 95-120, J. O . A. Abreu \& V. Nobre, trad.). Rio de Janeiro: Imago. (O riginal publicado em 1971).

Winnicott, D. W. (1984). Consultas terapêticas em psiquiatria infantil (J. M. X. Cunha, trad.). Rio de Janeiro: Imago. (O riginal publicado em 1971).

Winnicott, D. W. (1987). The Pigge relato do tratamento psicanalítico de uma menina (E. P. Vieira \& R. L. Martins, trad.). Rio de Janeiro: Imago. (O riginal publicado em 1977).

Winnicott, D. W. (1990a). Comunicação e falta de comunicação levando ao estudo de certos opostos. Em O ambieteeos procssos dematuraçãa eturbs sobre a teeria do desendvimento emoional (pp. 163-174, I. C. S. Ortiz, trad.). Porto Alegre: Artes Médicas. (O riginal publicado em 1979).

Winnicott, D. W. (1990b). Os objetivos do tratamento psicanalítico. Em D. W. Winnicott (Ed.), O ambienteeos processos dematuraçãa etudbs sobrea teeria do desendvimeto emcional (pp. 152-155, I. C. S. Ortiz, trad.). Porto Alegre: Artes Médicas. (O riginal publicado em 1979).

Winnicott, D. W. (1990c). Natureza humana (D. L. Bogomoletz, trad.). Rio de Janeiro, Imago Editora. (O riginal publicado em 1988).

Winnicott, D. W. (1991). Hddingeinterpração(S. M. T. M. Barros, trad.). São Paulo: Martins Fontes. (O riginal publicado em 1972).

Winnicott, D. W. (1994a). A interpretação na psicanálise. Em C. Winnicott, R. Shepherd \& M. Davis (O rgs.), Explaraçes psicanalíticas D.W. Winnicatt (pp. 163-166, J. O. A. Abreu, trad.). Porto Alegre: Artes Médicas. (O riginal publicado em 1989).

Winnicott, D. W. (1994b). O medo do colapso (Breackdown). Em C. Winnicott, R. Shepherd \& M. Davis (O rgs.), Explaraçes psicanalíticas D.W. Winnicatt (pp. 70-76, J. 0. A. Abreu, trad.). Porto Alegre: Artes Médicas. (O riginal publicado em 1989).

Winnicott, D. W. (1994c). O valor da consulta terapêutica. Em C. Winnicott, R. Shepherd \& M. Davis (O rgs.), Explaraçes psicanalíticas D.W. Winnicatt (pp. 244-248, J. O. A. Abreu, trad.). 
Porto Alegre: Artes Médicas. (Original publicado em 1989).

Winnicott, D. W. (1994d). Melanie Klein: sobre o seu conceito da inveja. Em C. Winnicott, R. Shepherd \& M. Davis (O rgs.), Explaraçes psicanalíticas D.W. Winicatt (pp. 338-347, J. O. A. Abreu, trad.). Porto Alegre: Artes Médicas. (O riginal publicado em 1989).

Winnicott, D. W. (1994e). Sobre os elementos masculino e feminino ex-cindidos (Split off). Em C. Winnicott, R. Shepherd \& M. Davis (Orgs.), Explaraçás psicanalíticas D.W. Winnicatt (pp. 133150, J. O. A. Abreu, trad.). Porto Alegre: Artes Médicas. (O riginal publicado em 1989).

Winnicott, D. W. (1994f). O conceito de regressão clínica comparado com 0 de organização defensiva. Em C. Winnicott, R. Shepherd \& M. Davis (Orgs.), Exploraçás psicanalíticas D.W. Winicatt (pp. 151-156, J. O. A. Abreu, trad.). Porto Alegre: Artes Médicas. (O riginal publicado em 1989).
Winnicott, D. W. (1994g). Sobre "O uso de um objeto". Em C. Winnicott, R. Shepherd \& M. Davis (Orgs.), Explaraçes psicanalíticas D.W. Winnicatt (pp. 170-191, J. O. A. Abreu, trad.). Porto Alegre: Artes Médicas. (O riginal publicado em 1989).

Winnicott, D. W. (1999). A comunicação entre o bebê e a mãe e entre a mãe e o bebê: convergências e divergências. Em Winnicott, D. W. (Ed.), Osbabesese suas mães (pp. 79-92, J. L. Camargo, trad.). São Paulo: Martins Fontes. (Original publicado em 1987).

Winnicott, D. W. (2000). O ódio na contratransferência. Em Winnicott, D. W. (Ed.), Da pediatria à psicanálise obras escolhidas (pp. 277287, D . Bogomoletz, trad.). Rio de Janeiro: Imago. (O riginal publicado em 1958).

Reedbidbem28/ 03/ 2011 Reformuladoem12/ 09/ 2011 Aprovadbem13/09/ 2011

Sobre a autora:

Conceição Aparecida Serralha é professora adjunta da Universidade Federal do Triângulo Mineiro, com Mestrado e D outorado em Psicologia Clínica pela Pontifícia Universidade Católica de São Paulo. É membro associado da Sociedade Brasileira de Psicanálise Winnicottiana - SBPW, membro do Grupo de Filosofia e Práticas Psicoterápicas da Unicamp - GFPP e do Grupo de Estudo e Pesquisa em Psicanálise - GEPPSE, da UFTM.

Contato com a autora:

Alameda Uberaba 85, apto 101, Bairro Santa Mônica, CEP: 38408-287. Uberlândia - MG.

Email: serralhac@ hotmail.com 